\section{SUPREMACIA DO INTERESSE PÚBLICO SOBRE INTERESSE PRIVADO EM FACE DOS DIREITOS FUNDAMENTAIS}

Recebimento do artigo: 12/04/2007 Aprovado em: 14/04/2007

\section{Ricardo Catunda N. Guedes Prof a Adriana Zawada Melo}

\section{Sumário}

1 Evolução histórica dos direitos fundamentais. 2 Etapas de interpretação dos direitos humanos. 3 Imprecisão no uso da expressão "direitos humanos" e inexistência de fundamento absoluto. 4 Restrições de direitos. 5 Princípios da razoabilidade e da proporcionalidade e o dogma da supremacia do interesse público. 6 Conclusões.

\section{Resumo}

$\mathrm{O}$ artigo analisa a evolução das doutrinas dos direitos fundamentais, verificando o atual entendimento do direito pátrio, em consonância com a Constituição de 1988. Nesse contexto, busca identificar validade de antigo dogma da supremacia do interesse público sobre o interesse particular - tendo em vista as disposições quanto aos direitos fundamentais na Carta Magna vigente.

\section{Palavras-chave}

Direitos fundamentais. Supremacia. Interesse público. Constituição.

\begin{abstract}
The article analyzes the development of the doctrines of the fundamental rights, verifying the current agreement in our law, according to the 1988's Constitution. In this context, it reaches to identify the possibility of applications of the old dogma of the supremacy of the public interest above the particular interest - observing the rules about the fundamental rights in our Constitution.
\end{abstract}

\section{Key words}

Fundamental rights. Supremacy. Public interest. Constitution. 


\section{Evolução histórica dos direitos fundamentais}

$\mathrm{Na}$ busca de eventual supremacia do interesse público sobre o privado como cláusula geral de restrição de direitos fundamentais, deve-se, inicialmente, tentar esclarecer significado e alcance da expressão direitos fundamentais, analisando a evolução histórica e o processo de constitucionalização ou de positivação desses direitos.

Poder-se-ia estabelecer como marco inicial dos direitos fundamentais a Magna Carta da Inglaterra (1215), como motivadora da inserção de direitos fundamentais nos textos constitucionais dos modernos Estados ocidentais.

Do mesmo país, o documento denominado Declaração de Direitos ("Bill of Rights"), de 1689, encerra o Regime Absolutista, de monarquia absoluta, no qual todo o poder emanava do rei e em seu nome era exercido, retirando do monarca as prerrogativas de legislar e de criar tributos e delimitando seu poder - transferindo tais funções e poderes para o Parlamento, além de outras garantias, protegendo dessas funções parlamentares em face do chefe de Estado, o Rei. O documento representa, em sua essência, a institucionalização da permanente separação de poderes no Estado (garantia institucional, ou forma de organização do Estado que protege os direitos fundamentais da pessoa humana). Ressalte-se que a teoria clássica da divisão dos poderes foi concebida para garantir, de certa forma, a progressiva separação entre política e direito - com neutralização política do Judiciário - e se tornará um dos elementos fundamentais para o aparecimento de nova forma de saber jurídico: a ciência do direito do século XIX.

Com a experiência jurídica dos séculos XVI a XVIII, o direito torna-se cada vez mais direito escrito, fato motivado tanto pelo rápido crescimento da quantidade de leis emanadas do poder constituído, como pela redação oficial e decretação da maior parte das regras costumeiras. Essa busca pelo direito na forma escrita acontece tanto para aumento da segurança e da precisão de seu entendimento, como aguça também a consciência dos limites. A relevância do costume, do direito não escrito sobre o escrito, vai paulatinamente se invertendo, tendo a contribuição do aparecimento do Estado Absolutista e do desenvolvimento progressivo da concentração do poder de legislar.

Essas transformações culminam em duas novas condicionantes, uma de natureza política (a noção de soberania nacional e o princípio da separação dos poderes), e outra de natureza técnico-jurídica (o caráter privilegiado que a lei assume como fonte do direito e a concepção do direito como sistema de normas postas). 
Nesse contexto insere-se a Declaração dos Direitos do Homem e do Cidadão, de 1789, na França, que em seu artigo $3^{\circ}$ proclamava: “O princípio de toda soberania reside essencialmente na nação". A soberania, a efetividade da força pela qual as determinações de autoridade são observadas e tornadas de observação incontornável, mesmo por meio de coação, antes residia no rei, simbolizando o centro único de normatividade, que é substituído pela nação, conceito mais abstrato e mais maleável, permitindo a manutenção do caráter uno, indivisível, inalienável e imprescritível da soberania - de acordo com o princípio da divisão dos poderes que, por sua vez, origina a concepção do poder judiciário com caracteres próprios e autônomos e com possibilidade de atuação limitada.

A positivação dos direitos fundamentais ganhou concreção a partir da Revolução Francesa de 1789, prevendo de forma precisa a proclamação da liberdade, da igualdade, da propriedade e das garantias individuais liberais (de forma quase simultânea com as declarações formuladas pelos Estados americanos no século XVIII, iniciadas pela declaração do Estado de Virgínia, de 12 de junho de 1776).

O denominado Direito Racional (que se estabelece entre os séculos XVII e XIX, aproximadamente) caracteriza-se pela influência dos sistemas racionais na teoria jurídica. A partir do Renascimento, o direito perde, progressivamente, seu caráter sagrado, sendo tal dessacralização acompanhada pela tecnização do saber jurídico e da equivalente perda de seu caráter ético (anteriormente cultuado na era Medieval).

O humanismo renascentista modifica a legitimação do Direito Romano, purificando e refinando o método da interpretação dos textos, inserindo-se a ciência moderna na teoria jurídica.

O jusnaturalismo moderno introduz o conceito de sistema, que pressupõe a correção e a perfeição formal da dedução, envolvendo mecanicismo, organismo e ordenação - ao direito privado europeu. A teoria jurídica européia se transforma: de mera teoria da exegese e da interpretação de textos singulares, passa a receber um caráter lógico-demonstrativo de um sistema fechado, cuja estrutura dominou e até hoje domina códigos e compêndios jurídicos.

De forma simplificada, poder-se-ia estabelecer que na Antiguidade Clássica o direito era fenômeno de ordem sagrada, de acordo com vida e tradição romana, decorrente de um saber de natureza ética: a prudência.

$\mathrm{Na}$ Idade Média mantém o caráter sagrado, adquirindo, porém, dimensão transcendente com sua cristianização, possibilitando que o saber prudencial apareça com traços dogmáticos - o direito tem origem divina e como tal deve ser recebido, aceito e interpretado pela exegese jurídica. 
Após o Renascimento há o processo de dessacralização do direito: reconstrução, pela razão, das regras de convivência. O processo de racionalização, baseado em razão sistemática, vai sendo assimilado pelo recente fenômeno do Estado Moderno - originando o direito como regulador nacional, ou supranacional.

O caráter fundamental do Direito Natural, conforme Pufendorf, está em sua função imperativa e não em sua função indicativa. Pela função indicativa, a norma jurídica apenas mostra o conteúdo da prescrição, enquanto por sua função imperativa ela nos obriga a fazer ou a deixar de fazer alguma coisa ${ }^{1}$.

Ainda conforme lições do Prof. Tércio Sampaio Ferraz, o mencionado jurista desenvolve sistemática jurídica característica, através da conjugação da dedução racional com a observação empírica (observando-se o dualismo cartesiano do método analítico e sistemático). Divide as normas de Direito Natural em absolutas (que obrigam independentemente das instituições estabelecidas pelo próprio homem) e hipotéticas (dotadas de certa variabilidade e flexibilidade, possibilitando ao Direito Natural uma espécie de adequação à evolução temporal).

O fundamento do chamado positivismo jurídico, corrente dominante no século XIX, é de que só existe um direito, o positivo, nos termos em seguida expostos.

Deve-se esclarecer, anteriormente, que há um sentido filosófico e um sentido sociológico de positivação. No primeiro, positivação designa o ato de positivar, isto é, de estabelecer direito por força de ato de vontade, seguindo-se daí a tese segundo a qual todo e qualquer direito é fruto de atos dessa natureza, ou seja, o direito é um conjunto de normas que valem por força de serem postas pela autoridade constituída e só por força de outra posição podem ser revogadas. É um sistema fechado, que não permite lacunas (exigência de acabamento) ${ }^{2}$. Ora, à medida que tais atos de vontade são decisórios, positivação passa a ser termo correlato de decisão. Direito positivo é aquele posto por decisão e, além disso, aquele cujas premissas da decisão que o põem também são postas por decisão.

\footnotetext{
${ }^{1}$ Cf. apertada síntese de ensinamentos trazidos por Tércio Sampaio Ferraz (FERRAZ JÚNIOR, Tércio. Introdução ao estudo do direito. 2. ed. São Paulo: Atlas, 1994, p. 65-79; 174-175). ${ }^{2}$ Para Norberto Bobbio (BOBBIO, Norberto. Teoria do ordenamento jurídico. 10. ed. Brasília: Editora Universidade de Brasília, 1999, p. 71) sistema é "uma totalidade ordenada, um conjunto de entes entre os quais existe uma certa ordem. Para que se possa falar de uma ordem, é necessário que os entes que a constituem não estejam somente em relacionamento com o todo, mas também num relacionamento de coerência entre si”. Conforme Tércio Sampaio Ferraz (FERRAZ JÚNIOR, op. cit., p. 174-175), "em princípio, um ordenamento é um conjunto de normas". Porém, "além de ser um conjunto de elementos normativos (normas) e não-normativos, é também uma estrutura, isto é, um conjunto de regras que determinam as relações entre os elementos". Continuando, esclarece que "o conjunto destas regras e das relações por elas estabelecidas é a estrutura. O conjunto dos elementos é apenas o repertório", concluindo que "o sistema é um complexo que se compõe de uma estrutura e um repertório. Nesse sentido, ordenamento é um sistema”.
} 
No sentido sociológico, positivação, no século XIX, é fenômeno representado pela crescente importância da lei votada pelos parlamentos como fonte do direito. Pela necessidade de segurança da sociedade burguesa, exigindo a valorização dos preceitos legais no julgamento dos fatos, desenvolve-se a poderosa Escola da Exegese, de grande influência nos países onde dominou o espírito napoleônico. A redução do jurídico ao legal foi crescendo durante o século XIX, até culminar no chamado legalismo ${ }^{3}$. Tal exigência foi política e também econômica, pois a Revolução Industrial impõe aumento na velocidade das transformações tecnológicas, reclamando respostas mais prontas do direito, que o direito costumeiro não podia fornecer. Ao contrário, o direito reduzido ao legal fazia crescer a disponibilidade temporal sobre o direito, cuja validade foi sendo percebida como algo maleável, manipulável, adaptável e podendo ser tecnicamente limitada e controlada no tempo ${ }^{4}$.

A concepção da lei como principal fonte do direito chamará a atenção para a possibilidade de o direito mudar toda a vez que mude a legislação. O direito deixa de ser um ponto de vista em nome do qual mudanças e transformações são rechaçadas, algo estável em face das mudanças do mundo (por tradição, para os romanos, pela revelação divina, na Idade Média, ou pela razão, na Era Moderna). A consciência social do século XIX aceita a mutabilidade do direito como usual: a idéia de que, em princípio, todo direito mude torna-se a regra, e que algum direito não mude, a exceção - sendo que esta institucionalização da mutabilidade do direito corresponde ao chamado fenômeno da positivação do direito.

A denominada Dogmática Jurídica desenvolve-se e atribui a seus conceitos um caráter abstrato, permitindo emancipação das necessidades cotidianas dos diversos interesses - possibilitando neutralização dos interesses concretos na formação do

\footnotetext{
${ }^{3}$ Conforme Hans Kelsen (KELSEN, Hans. Teoria pura do direito. 6. ed. São Paulo: Martins Fontes, 1998, p. 215-217), "o fundamento de validade de uma norma apenas pode ser a validade de uma outra norma. Uma norma que representa o fundamento de validade de uma outra norma é figurativamente designada como norma superior, por confronto com uma norma que é, em relação a ela, a norma inferior", estabelecendo que "todas as normas cuja validade pode ser reconduzida a uma e mesma norma fundamental formam um sistema de normas, uma ordem normativa. A norma fundamental é a fonte comum da validade de todas as normas pertencentes a uma e mesma ordem normativa, o seu fundamento de validade comum." Continua esclarecendo o autor: "Mas a indagação do fundamento de validade de uma norma não pode, tal como a investigação da causa de um determinado efeito, perder-se no interminável. Tem de terminar numa norma que se pressupõe como a última e a mais elevada. Como norma mais elevada, ela tem de ser pressuposta, visto que não pode ser posta por uma autoridade, cuja competência teria de se fundar numa norma ainda mais elevada. A sua validade já não pode ser derivada de uma norma mais elevada, o fundamento da sua validade já não pode ser posto em questão. Uma tal norma, pressuposta como a mais elevada, será aqui designada como norma fundamental (Grundnorm)".

${ }^{4}$ Cf. FERRAZ JÚNIOR, Tércio. Introdução ao estudo do direito. 2. ed. São Paulo: Atlas, 1994, p. $72-75$. 
278 direito, já exigida pela separação dos poderes e pela autonomia do poder judiciário. Normas, conceitos e regras passam a ser o objeto da ciência dogmática, devendo o jurista buscar unificação construtiva dos juízos normativos e esclarecimento de seus fundamentos, e, a partir do final do século XIX, para a autolimitação do pensamento jurídico ao estudo da lei positiva e ao estabelecimento da tese da estabilidade do direto.

$\mathrm{Na}$ fase do pós-positivismo, os princípios atingem o cume da hierarquia axiológico-normativa na estrutura dos ordenamentos jurídicos. A percepção de que o trabalho do legislador revela critério de valoração, segundo as aspirações das comunidades que representa, e de acordo com ideais superiores de justiça, assim como a verificação de que a jurisprudência, mediante a aplicação dessas valorações, as confirma, são as noções de partida da Jurisprudência de Valores. Ao longo deste século, a jurisprudência de valores (ou a jurisprudência dos princípios, visto que sinônimos para alguns autores, como Paulo Bonavides ${ }^{5}$ ), passou por inúmeras variações de natureza metodológica, todas voltadas para a tentativa de se conquistar, de forma inabalável, a proclamação da normatividade dos princípios.

Ao contrário das regras, que operam em base binária do tipo tudo ou nada (all or nothing), os princípios, por sua distinta natureza, funcionam como o direito por trás do direito (law behind law), em outro grau de aplicabilidade. As regras são criadas pelo legislador e referenciam-se a situações jurídicas que, uma vez verificadas, fazem incidir o resultado ou a conseqüência jurídica previamente estabelecidos pela norma. Já, os princípios têm maior abrangência, irradiam-se por todo o sistema normativo e não se dirigem a uma situação jurídica em particular.

Em situações nas quais o julgador, buscando soluções para o caso concreto, não encontra respostas imediatas no texto legal, deve socorrer-se dos princípios, que delineiam a orientação geral da política jurídica vigente.

A elevação dos princípios a uma posição hegemônica dentro dos sistemas jurídicos afastou deficiências do pensamento positivista, e viabilizou recuperação de alguns aspectos do pensamento jusnaturalista.

Conforme lição do Prof. Paulo Bonavides ${ }^{6}$, verbis:

Em resumo, a teoria dos princípios chega à presente fase do póspositivismo com os seguintes resultados já consolidados: a passagem dos princípios da especulação metafísica e abstrata para o campo concreto e positivo do Direito, com baixíssimo teor de densidade normativa; a transição

\footnotetext{
${ }^{5}$ Cf. BONAVIDES, Paulo. Curso de direito constitucional. 19. ed. São Paulo: Malheiros, 2006, p. $472-$ 476. O autor afirma que para a Nova Hermenêutica, a moderna interpretação da Constituição deriva do inconformismo de alguns juristas com o positivismo lógico-formal da época do Estado liberal.

${ }^{6}$ Cf. BONAVIDES, op. cit., p. 294.
} 
crucial da ordem jusprivatista (sua antiga inserção nos Códigos) para a órbita juspublicística (seu ingresso nas Constituições); a suspensão da distinção clássica entre princípios e normas; o deslocamento dos princípios da esfera da jusfilosofia para o domínio da ciência jurídica; a proclamação de sua normatividade; a perda de seu caráter de normas programáticas; o reconhecimento definitivo de sua positividade e concretude por obra sobretudo das Constituições; a distinção entre regras e princípios, como espécies diversificadas do gênero norma, e, finalmente, por expressão máxima de todo este desdobramento doutrinário, o mais significativo de seus efeitos: a total hegemonia e preeminência dos princípios.

\section{Etapas de interpretação dos direitos humanos}

A evolução histórica, sintetizada anteriormente, tem utilidade para se analisar as diferentes fases de interpretação de direitos humanos, de acordo com o momento histórico, com a vagueza conceitual ou com as imprecisões em relação à expressão direitos bumanos ${ }^{7}$.

De acordo com lições de Luís Roberto Barroso $^{8}$, o jusnaturalismo funda-se na existência de um direito natural, com origem associada à cultura grega. Tem variantes, resumidas em duas versões: uma em que a lei é estabelecida pela vontade de Deus e outra em que a lei é editada pela razão. Na Idade Moderna, associando-se ao Iluminismo (na fase denominada jusnaturalismo racionalista), o homem possui um rol de direitos naturais que deveriam ser preservados e respeitados, inclusive pelo Estado. Tais direitos naturais passam a ser agregados aos textos constitucionais, sendo que, aliado ao processo de codificação, surge a Escola da Exegese, pela qual há apego ao texto e à interpretação gramatical e histórica (com ideal de ser objetiva e neutra).

O positivismo almejava "cientificizar" todo o conhecimento, inclusive os sociais, com pretensão, por exemplo, de criar ciência jurídica com características semelhantes às ciências exatas e naturais. Para essa corrente, norma é definida como ato emanado do Estado com caráter imperativo e força coativa, e a ciência deveria fundar-se em juízos de fato, não em juízos de valor - almejando conhecimento puramente objetivo da realidade. O positivismo jurídico buscava idéias e conceitos dogmáticos, que dispensassem justificação, reduzindo direito ao conjunto de normas em vigor. O intérprete deveria ser objetivo e neutro, com atitude cognoscitiva fundada em juízos de fato, separando de forma rígida ordenamento jurídico de valores éticos (inclusive quanto aos direitos fundamentais, que existiriam se postos no ordenamento em normas válidas e vigentes), e aplicando hermenêutica meramente formal no ato de interpretação.

\footnotetext{
${ }^{7}$ Cf. PEREZ-LUÑO, Antonio Enrique. Derechos humanos, estado de derecho y constitución. 2. ed. Madrid: Tecnos, 1984, p. 21-39. O autor faz referência a pensamentos de Norberto Bobbio.

${ }^{8}$ BARROSO, Luís Roberto. Interpretação e aplicação da constituição. 6. ed. São Paulo: Saraiva, 2004, p. 318-333.
} 
Os excessos em nome da corrente positivista conduziram às atrocidades cometidas em nome da lei, notadamente no fascismo e nazismo, e, em reação a elas, surge nova hermenêutica, denominada pós-positivismo, pois o ideal de objetivismo e neutralidade do positivismo tornou-se ideologia para, além de tentar entender o Direito, agir no sentido de como querer o Direito. Essa nova hermenêutica reaproxima o Direito da ética, adotando a teoria dos princípios, que juntamente com as regras, compõem o conjunto das normas jurídicas. Os princípios têm maior grau de abstração, maior carga valorativa, fundamento ético e decisão política relevante, indicando caminho a tomar. Como o Direito passa a ser tomado como sistema aberto de valores, no qual a Constituição traz conjunto de regras e princípios (expressos ou não) destinados a realizá-los, o intérprete deve utilizar a ponderação de valores (ou ponderação de interesses), levando em conta as circunstâncias de cada caso para chegar a resultado socialmente desejável, tentando sacrifício mínimo de princípios ou direitos fundamentais envolvidos naquele caso.

Para Perez-Luño ${ }^{10}$, os direitos fundamentais estão positivados em dois sistemas: em cláusulas gerais, que aparecem na forma de valores ou princípios, e em casuístico, que se positiva em normas específicas, que dão concretude e pormenorizam os direitos básicos. Pode haver sistema misto, que é o mais freqüentemente utilizado pelas Constituições.

Os valores constitucionais traduzem as prioridades e os fundamentos do constituinte para a convivência social, são opções éticas e sociais que devem nortear as decisões políticas, jurídicas, econômicas e culturais. Trazem o contexto histórico-espiritual para interpretação da Constituição e, especialmente, para interpretação e aplicação dos direitos fundamentais. Integram o sistema normativo e tendem a ser concretizados em princípios que explicitam seu conteúdo, com menor grau de abstração.

Assim, as normas poderiam ser tomadas como o conjunto dos valores, dos princípios e das regras. Os valores seriam espécie de metanormas em relação aos princípios e seriam normas de terceiro grau em relação às regras (ou disposições específicas).

Observa-se que um valor ou princípio constitucional não necessita estar expresso em regra específica para que seja invocado ou aplicado - podendo ser aplicado de imediato por se tratar de norma constitucional.

\footnotetext{
9 Apud Luís Roberto Barroso(BARROSO, Luís Roberto. Interpretação e aplicação da constituição. 6. ed. SãoPaulo: Saraiva, 2004, p. 324), citando pensamento de Norberto Bobbio (BOBBIO, Norberto. O positivismo jurídico, p. 223-224).

${ }^{10}$ Cf. PEREZ-LUÑO, Antonio Enrique. Derechos humanos, estado de derecho y constitución. 2. ed. Madrid: Tecnos, 1984, p. 286-292.
} 


\section{Imprecisão no uso da expressão "direitos humanos" e inexistência de fundamento absoluto}

Para Perez-Luño", a significação heterogênea da expressão "direitos humanos", tanto na doutrina como na prática, tem contribuído para tornar este conceito um paradigma de equívocos. Na maioria das ocasiões, a expressão não é efetivamente definida, ou sua definição se dá utilizando termos pouco satisfatórios. Reporta-se ao estudo de Bobbio, que distinguiu três tipos de definições dos direitos humanos:

a) tautológicas: que não trazem nenhum novo elemento que possa caracterizar tais direitos (como "direitos humanos são os que correspondem aos humanos pelo fato de serem humanos");

b) formais: que não especificam o conteúdo desses direitos, limitando-se a trazer alguma indicação sobre seu estatuto desejado ou proposto (como: "direitos humanos são os que pertencem ou devem pertencer a todos os homens, dos quais nenhum homem deve ser privado");

c) teleológicas: que apelam para certos valores essenciais, suscetíveis de diversas interpretações (como: “direitos humanos são aqueles imprescindíveis para o aperfeiçoamento da personalidade humana, para o progresso social ou para o desenvolvimento da civilização").

Para o ilustre pensador, grande parte dos equívocos, da desorientação teórica e prática suscitada pelo significado equivocado da expressão "direitos humanos" vem da própria ambiguidade que reveste a pergunta "o que são os direitos humanos?" - sendo improvável, na prática, que uma definição pudesse revelar todos os fenômenos cobertos pelos termos que constam na expressão.

Para a análise lingüística da expressão "direitos humanos" devem-se fixar os limites internos e externos - para maior precisão do alcance de seu significado. Para tanto, devem-se distinguir, de um lado, os objetos que podem ser denotados pelos termos e os que não podem cobrir a expressão, confrontando com outras categorias afins e, por outro lado, que podem identificar o contexto em que os direitos humanos tenham significado.

Nesse sentido, o autor relaciona a expressão com outros termos ou expressões que possam designar realidade muito próxima, ou até a mesma realidade, tais como: a) direitos humanos e direitos naturais; b) direitos humanos e direitos fundamentais; c) direitos humanos e direitos subjetivos; d) direitos humanos e direitos públicos

${ }^{11}$ PEREZ-LUÑO, Antonio Enrique. Derechos humanos, estado de derecho y constitución. 2. ed. Madrid: Tecnos, 1984, p. 25-29. 
subjetivos; e) direitos humanos e direitos individuais; f) direitos humanos e liberdades públicas.

Para Norberto Bobbio 12 , "valor absoluto" seria um estatuto aplicado a pouquíssimos direitos do homem, válidos em todas as situações e para todos os homens sem distinção. Teria fundamento absoluto o direito humano inafastável, qualquer que fosse a situação e as pessoas envolvidas - situação privilegiada praticamente inexistente, em que tais direitos fundamentais absolutos não estariam concorrendo com outros direitos, também fundamentais. Entre raros exemplos, poderiam ser citados os direitos de não ser escravizado e o de não ser torturado. A decisão para estabelecer qual direito fundamental prevalece sobre o outro é extremamente variável. A questão deve ser resolvida com base em critério de valores, podendo, entretanto, ser analisada sobre valores de diferentes esferas: i) valores da consciência individual; ii) do sistema de valores do grupo ao qual o indivíduo pertence; e iii) valores da consciência moral da humanidade num dado momento histórico.

Tais critérios são muito vagos para que seja concretizado um princípio de certeza, que parece ser almejado um sistema jurídico imparcial a fim de distribuir razão e não-razão.

Assim, não há categoria homogênea de direitos humanos: são relativos e constituem categoria heterogênea: seu conjunto contém direitos incompatíveis entre si, pois a aplicação de um, em alguns casos, implica restrição ou suspensão da proteção de outro, sendo a resolução diversa para cada grupo de valor adotado (e diversa para cada sociedade, com valores individuais e coletivos diferentes de outras).

Portanto, para o ilustre jurista, mais importante do que a busca de fundamentação dos direitos humanos é a busca pelo modo mais seguro de garanti-los, a busca pela sua proteção. É o problema mais urgente a ser enfrentado, pois considera que o problema de fundamentação foi resolvido na Declaração Universal dos Direitos do Homem, da ONU (de 1948) - que concebeu sistema de valores universalmente aceito.

\section{Restrições de direitos}

Para Robert $\mathrm{Alexy}^{13}$, as restrições de direitos fundamentais são normas que restringem a realização de princípios fundamentais. A restrição de direito fundamental resulta da determinação do conteúdo e do alcance das restrições,

\footnotetext{
${ }^{12}$ Cf. PEREZ-LUÑO, Antonio Enrique. Derechos humanos, estado de derecho y constitución. 2. ed. Madrid: Tecnos, 1984, p. 21-39.

${ }^{13}$ Cf. ALEXY, Robert. Teoria de los derechos fundamentales.Madrid: Centro de Estúdios Políticos y Constitucionales, 2001. p. 267-291.
} 
bem como da diferença entre restrições de uma parte e de regulamentações, configurações e concreções, de outra.

Poderia supor-se que existem: o direito e suas restrições, isto é, o direito em si, sem restrições, e o direito restrito, na denominada "teoria externa" - que admite que nos ordenamentos jurídicos os direitos se apresentem primordial ou exclusivamente como direitos restritos, mas também é aceita a existência dos direitos sem restrições. Ainda conforme essa teoria, não existe relação necessária entre o conceito do direito e o da sua restrição. A relação advém da necessidade externa ao direito, de compatibilizar os direitos de diferentes indivíduos, bem como dos direitos individuais e dos bens coletivos.

Em sentido oposto, para a denominada "teoria interna" existe apenas: o direito com um determinado conteúdo. O conceito de restrição é substituído pelo de limite, que são restrições imanentes.

A adoção de uma ou de outra teoria dependerá de como os direitos fundamentais são tomados: se como regras ou princípios, e se as posições são definitivas ou prima facie; partindo-se de posições definitivas, refutar-se-ia a teoria externa, e se partindo prima facie refuta-se-ia a teoria interna.

O citado autor se baseia e cita Friedrich Klein, para o qual há impossibilidade lógica de se falar em restrições de direitos quando se parte exclusivamente de posições definitivas.

Se é possível ordenar ou proibir uma ação, então não existe nenhum direito ao livre arbítrio do indivíduo. Normas que privam de algo sobre o qual não existe direito algum não podem restringir nenhum direito. No sentido oposto, se há direito que fica ao livre arbítrio do indivíduo, para exercê-lo ou não, as normas que o obrigam ou o proíbem não restringem tal direito, mas o violam. Se só existem posições definitivas, os direitos fundamentais não poderiam ser restringidos, mas somente as liberdades fundamentais - que existem quando uma alternativa de ação é dada ao indivíduo por uma norma jusfundamental, sendo que aqui também se devem diferenciar posições definitivas e prima facie. Se é possível partir-se da existência somente de posições definitivas, também não é correto admitir restrição de liberdades fundamentais - não se poderia admitir restringidas posições jusfundamentais, mas somente bens jusfundamentais protegidos.

Por outro lado, adotando-se a teoria dos princípios, na qual o que se restringiria não seriam posições definitivas, mas prima facie, chega-se a resultado oposto. Não se restringe não só um bem protegido por normas de direitos fundamentais, mas sim um direito prima facie garantido por normas jusfundamentais. Pelo modelo dos princípios, as restrições de direitos fundamentais são admissíveis, estando correta a teoria externa, e incorreta a de Klein, na conclusão de Alexy. 
Reservas legais seriam normas de competência pelas quais o legislador autoriza imposição de restrições aos direitos fundamentais. Tais restrições são impostas por normas, sendo requisito essencial que se tratem de normas constitucionais - caso contrário terá caráter de intervenção, não de restrição. Não são restrições, propriamente ditas, mas fundamentam possibilidade jurídica de restrição de direito fundamental, podendo haver competência para imposição de restrição sem que nunca seja exercida (nunca ocorrendo, conseqüentemente, a restrição). Tais normas de competência diferenciam-se, portanto, das normas de comando ou proibição dirigidas aos indivíduos.

Uma regra é restrição de direito fundamental quando, com sua vigência, aparece, no lugar de uma liberdade fundamental prima facie ou de um direito fundamental prima facie, uma não-liberdade definitiva ou um não-direito definitivo de igual conteúdo (regra que obriga motociclista a usar capacete restringe direito fundamental, substituindo uma liberdade prima facie por uma não-liberdade definitiva).

Princípios também podem ser restrições de direitos fundamentais, da mesma forma: quando, com sua aplicação, no lugar de uma liberdade fundamental prima facie ou de um direito fundamental prima facie, aparece uma não-liberdade definitiva ou um não-direito definitivo de igual conteúdo.

Cabe observar que tal limitação dos direitos fundamentais deve ter como pressuposto sua previsão em lei geral, abstrata e suficientemente densa e determinada, de modo a gerar previsibilidade e segurança jurídica. Serão consideradas inválidas as restrições a direitos fundamentais estabelecidas em termos muito vagos, pois permitem ingerências imprevisíveis no âmbito de proteção do direito, conferindo ao aplicador da norma uma discricionariedade exagerada, além de facilitar ocorrência de arbítrio ${ }^{14}$.

Assim, os limites aos direitos fundamentais podem apresentar-se, basicamente, sob três formas diferentes: (a) estabelecidos diretamente na própria Constituição; (b) autorizados pela Constituição, quando esta prevê a edição de lei restritiva; e (c) decorrer finalmente de restrições não expressamente referidas no texto constitucional. ${ }^{15}$

\footnotetext{
${ }^{14} \mathrm{Cf}$. SARMENTO, Daniel. Colisões entre direitos fundamentais e interesses públicos. In: SARMENTO, Daniel; GALDINO, Flávio (org.). Direitos fundamentais: estudos em homenagem ao professor Ricardo Lobo Torres. Rio de Janeiro: Renovar, 2006, p. 306-308.

${ }^{15}$ SARMENTO, op. cit., p. 302. 


\section{Princípios da razoabilidade e da proporcionalidade e o dogma da supremacia do interesse público}

Os princípios da razoabilidade e da proporcionalidade são utilizados como mecanismos para controlar a discricionariedade legislativa e administrativa. Pode-se diferenciá-los adotando o da razoabilidade como instrumento de controle de atos normativos e o da proporcionalidade como instrumento de controle de atos administrativos. Ambos, porém, são aplicados para invalidar atos nos quais: i) não há adequação entre fim perseguido e meio empregado; ii) não é exigível ou necessária tal medida, ou iii) não há proporcionalidade, em sentido estrito (a medida traz resultado mais negativo do que se não fosse tomada). Com aplicação desses princípios, o Judiciário deve buscar o melhor resultado, isto é, buscar a realização dos direitos fundamentais (dos valores constitucionais), o resultado socialmente desejável.

De acordo com Daniel Sarmento ${ }^{16}$, “o dogma vigente entre os publicistas brasileiros, da supremacia do interesse público sobre o particular, parece ignorar nosso sistema constitucional, que tem como uma das suas principais características a relevância atribuída aos direitos fundamentais”. Grande objeção ao princípio da supremacia do interesse público ${ }^{17}$ sobre o particular é sua incompatibilidade com o princípio da proporcionalidade, importante parâmetro para aferição da constitucionalidade das restrições aos direitos fundamentais. O princípio da proporcionalidade tem sua vigência no ordenamento brasileiro hoje reconhecida pela doutrina e jurisprudência, trazendo critérios controláveis para resolução de colisões envolvendo interesses constitucionais.

O mencionado princípio da proporcionalidade poderia ser desmembrado em três subprincípios, assim sintetizados por Luís Roberto Barroso:

\footnotetext{
(a) da adequação, que exige que as medidas adotadas pelo Poder Público se mostrem aptas a atingir os objetivos pretendidos; (b) da necessidade ou exigibilidade, que impõe a verificação da inexistência de meio menos gravoso para atingimento dos fins visados; e da (c) proporcionalidade em sentido estrito, que é a ponderação entre o ônus imposto e o benefício
}

\footnotetext{
${ }^{16}$ SARMENTO, Daniel. Colisões entre direitos fundamentais e interesses públicos. In: SARMENTO, Daniel; GALDINO, Flávio (org.). Direitos fundamentais: estudos em homenagem ao Professor Ricardo Lobo Torres. Rio de Janeiro: Renovar, 2006, p. 301; 309.

${ }^{17}$ Deve-se atentar que uso de termos podem contaminar algumas interpretações, conforme alerta Müller (MÜLLER, Friederich. Quem é o povo? A questão fundamental da democracia. Tradução de Peter Naumann. São Paulo: Max Limonad, 1998, p. 115) sobre a utilização, por exemplo, de "povo", palavra gasta e mal empregada, muitas vezes utilizada para legitimar situações antidemocráticas, em que os verdadeiros interesses populares são olvidados em favor dos interesses privados de grandes grupos econômicos.
} 

do cidadão. ${ }^{18}$

O próprio momento histórico da promulgação da Constituição, combatendo anterior prática autoritária do Estado e de sua relação com as pessoas, que relegava os direitos fundamentais a um plano secundário e periférico, além da análise da topologia dos direitos fundamentais no atual texto, antes das normas relacionadas à estrutura, aos poderes e às competências do Estado, demonstram que não se pode mais utilizar o antigo dogma da supremacia do interesse público sobre o interesse particular.

O trecho do pensamento de Daniel Sarmento, a seguir transcrito, é esclarecedor:

E mais, por todas as razões acima aventadas, entendemos que, diante de conflitos entre direitos fundamentais e interesses públicos de estatura constitucional, pode-se falar, na linha de Alexy, numa "precedência prima facie” dos primeiros. Esta precedência implica na atribuição de um peso inicial superior a estes direitos no processo ponderativo, o que significa reconhecer que há um ônus argumentativo maior para que interesses públicos possam eventualmente sobrepujá-los. Assim, o interesse público pode até prevalecer diante do direito fundamental, após um detido exame calcado sobretudo no princípio da proporcionalidade, mas para isso serão necessárias razões mais fortes do que aquelas que permitiriam a "vitória" do direito fundamental. E tal idéia vincula tanto o legislador - que se realizar ponderações abstratas que negligenciarem esta primazia prima facie dos direitos fundamentais poderá incorrer em inconstitucionalidade - como os aplicadores do Direito - juízes e administradores - quando se depararem com a necessidade de realização de ponderações in concreto. ${ }^{19}$

\section{Conclusões}

O Estado Democrático de Direito admite supremacia dos direitos fundamentais sobre os interesses da coletividade, pois o moderno civismo, o civismo nos moldes de nossa Constituição, não admite antiga visão de súditos perante o Estado, que deve ser alterada para noção de cidadãos. Cidadãos que formam a vontade coletiva e são detentores de direitos fundamentais, que devem ser preservados, não mutilados pelo interesse público.

Normas que não traduzem comandos constitucionais, que não estejam de acordo com valores constitucionais, como os da justiça social e o da dignidade humana,

\footnotetext{
${ }^{18}$ BARROSO, Luís Roberto. Interpretação e aplicação da constituição. 6. ed. Saraiva: 2004, p. 209.

${ }^{19}$ SARMENTO, Daniel. Colisões entre direitos fundamentais e interesses públicos. In: SARMENTO, Daniel; GALDINO, Flávio (org.). Direitos fundamentais: estudos em homenagem ao professor Ricardo Lobo Torres. Rio de Janeiro: Renovar, 2006, p. 313.
} 
não podem ser aplicadas, pois, além de provocarem danos ao Estado Democrático de Direito, estabelecido já no preâmbulo da Carta Magna, nenhuma norma pode, em nome do interesse público, mutilar ou restringir direito fundamental, salvo em raras situações previstas constitucionalmente.

\section{Referências}

ALEXY, Robert. Teoria de los derechos fundamentales. Madrid: Centro de Estúdios Políticos y Constitucionales, 2001.

BARROSO, Luís Roberto. Interpretação e aplicação da constituição. 6. ed. São Paulo: Saraiva, 2004.

BOBBIO, Norberto. Teoria do ordenamento jurídico. 10. ed. Brasília: Editora Universidade de Brasília, 1999.

BONAVIDES, Paulo. Curso de direito constitucional. 19. ed. São Paulo: Malheiros, 2006.

FERRAZ JÚNIOR, Tércio Sampaio. Introdução ao estudo do direito. 2. ed. São Paulo: Atlas, 1994.

KELSEN, Hans. Teoria pura do direito. 6. ed. São Paulo: Martins Fontes, 1998.

MÜLLER, Friedrich. Quem é o povo? A questão fundamental da democracia. Tradução de Peter Naumann. São Paulo: Max Limonad, 1998.

PEREZ-LUÑO, Antonio Enrique. Derechos humanos, estado de derecho y constitución. 2. ed. Madrid: Tecnos, 1984.

SARMENTO, Daniel. Colisões entre direitos fundamentais e interesses públicos. In: SARMENTO, Daniel; GALDINO, Flávio. Direitos fundamentais: estudos em homenagem ao Professor Ricardo Lobo Torres. Rio de Janeiro: Renovar, 2006. p. 267-324. 